\title{
ALTERAÇÃO DE UM LAYOUT FUNCIONAL PARA LAYOUT CELULAR MOTIVADO PELOS FUNDAMENTOS DA MANUFATURA ENXUTA: ESTUDO DE CASO EM INDÚSTRIA DE TRANSFORMADORES
}

\author{
F. C. GADELHA', J. A. BESSA', L B. MOURA', D. A. BARROSO², J.W.M. MENEZES ${ }^{1}$ e A. R. ALEXANDRIA ${ }^{1^{*}}$ \\ ${ }^{1}$ Instituto Federal de Educação, Ciência e Tecnologia do Ceará \\ ${ }^{2}$ Omni Engenharia \\ auzuir@gmail.com*
}

Artigo submetido em julho/2013 e aceito em junho/2015

DOI: $10.15628 /$ holos.2015.1556

\section{RESUMO}

O presente trabalho apresenta o estudo de uma alteração de layout, de funcional para celular, motivado pelos fundamentos da manufatura enxuta. Tendo como objetivo verificar os benefícios de se utilizar a manufatura celular com fluxo enxuto (contínuo), apresenta como metodologia um estudo de caso, pós-fato, em uma indústria de transformadores, onde a mudança foi realizada. Para fundamentar o estudo, apresenta revisão dos temas: Sistema de Manufatura Enxuta e layout industrial, para, em seguida, trazer os dados apresentados por esta indústria, ainda em um arranjo físico funcional, antes da alteração, e, em seguida, nas células de manufatura com um fluxo enxuto, após a alteração, e realizar uma comparação entre ambos. Os resultados obtidos desta comparação apresentam ganhos como aumento de produção, em 20\%, e produtividade, em $56 \%$, redução de lead time, em $67 \%$, mão de obra direta, em $30 \%$, tempo de processamento, em 20\%, e área fabril, em 24\%, dentre outros, evidenciando os benefícios que a utilização de um layout celular e Manufatura Enxuta proporcionam.

PALAVRAS-CHAVE: Layout funcional, Layout Celular, Manufatura Enxuta.

\section{MODIFICATION OF A FUNCTIONAL LAYOUT FOR MOTIVATED CELULAR LAYOUT BY FOUNDATIONS OF LEAN MANUFACTURING: CASE STUDY IN TRANSFORMERS INDUSTRY}

\begin{abstract}
The current document presents the study of layout change from functional to cellular, motivated by the fundamentals of lean manufacturing. Aiming to verify the benefits of using Cellular Manufacturing with lean flow (continuous), presents as methodology a case study after the fact in a transformers industry where the change was performed. To support the study, it shows reviews of the themes: Lean Manufacturing System and industrial layout, for then, bring the data provided by this industry, still in a functional physical arrangement before the
\end{abstract}

changes, and then, in the manufacturing cells, with a lean flow, after the changing, and realize a comparison between both. The results obtained from this comparison, presents earnings with the increasing of $20 \%$ on production, and $56 \%$ on productivity, reduction of $67 \%$ on lead time, $30 \%$ on direct labor, $24 \%$ on processing time, and $24 \%$ on manufacturing area, among others, evidencing the benefits that a application of a cellular layout, and Lean Manufacturing provide.

KEYWORDS: Functional Layout, Cellular Layout, Lean Manufacturing 


\section{INTRODUÇÃO}

O crescimento da economia brasileira, nos últimos anos, provocou um acentuado aumento do consumo de energia, segundo a ANEEL (2008) - Agência Nacional de Energia Elétrica. Além disso, o Projeto Luz para Todos, criado em 2003 pelo Governo Federal, continua a expandir o acesso à energia elétrica, no país, levando "luz", sobretudo, aos habitantes das comunidades rurais mais distantes (MME, 2012). Se aliarmos a isso o fato de que o Brasil é um país de proporções continentais e que isso exige, para a transmissão desta energia, uma enorme rede de distribuição, pode-se facilmente observar o crescimento da demanda dos produtos que tornam possível a transmissão da energia. Condutores, postes, transformadores, só para citar alguns.

Com o crescimento da procura por transformadores, condutores e outros produtos necessários à transmissão de energia, surgiram muitas indústrias, em todo o país, buscando participar de uma fatia deste mercado, o que gerou um cenário competitivo onde só sobrevivem empresas capazes de produzir produtos com preço compatível, com qualidade, em lotes cada vez menores de itens diversificados e entregues no prazo determinado. Isto faz com que sejam necessários sistemas produtivos capazes de atender a estes requisitos e responder às exigências do mercado (LUZZI, 2004).

Visando manter seus clientes em um mercado tão acirrado e permanecer competitiva, uma indústria de transformadores, que é alvo do estudo deste trabalho, viu-se obrigada a repensar seu sistema produtivo de maneira a atender ao mercado e reverter um cenário de atrasos de pedidos e preços elevados, que nas condições atuais, não poderia mais existir. Para eliminar os atrasos de entrega é necessário reduzir o lead time (ciclo de realização de uma tarefa, trabalho, produto ou serviço), para reduzir custos é preciso minimizar os desperdícios (DE TREVILLE, 2014). A solução encontrada para alcançar estes objetivos foi uma alteração de layout, de um layout funcional para um layout celular, motivada pelos princípios da manufatura enxuta, ou lean manufacturing. Utilizando-se um layout de manufatura celular é possível estabelecer um fluxo contínuo, adotado no sistema de manufatura enxuta, capaz de proporcionar a redução de lead time necessária e ainda alcançar a redução de custo desejada (GUINATO, 2000).

A manufatura enxuta e o pensamento enxuto (lean thinking) têm sido adotados por empresas no mundo inteiro como arma para vencerem crises, permanecerem no mercado e continuarem crescendo (WOMACK; JONES; ROSS, 2004). Nascido na Toyota Motor Co e originalmente conhecido como Sistema Toyota de Produção (TPS), o Sistema de Manufatura Enxuta fundamenta-se na busca pela absoluta eliminação do desperdício (RICCl, 2014). No TPS são identificados sete tipos de desperdício (OHNO, 1997; SHINGO, 1996a): superprodução, espera, transporte, processamento, estoque, nos movimentos e na produção de produtos defeituosos.

Grande parte dos desperdícios identificados pelo Sistema Toyota de Produção, sobretudo os desperdícios de transporte, de estoque e de movimentação, são minimizados com a otimização do layout produtivo (SHINGO, 1996a) e, segundo Black (1998), é crítico o reconhecimento de que a implementação de células de manufatura (CM) é o primeiro passo para converter um sistema produtivo em sistema de manufatura enxuta (FRITZEN; SAURIN, 2014).

Com base no exposto, o problema a ser investigado é: quais os benefícios da utilização de um layout de manufatura celular com fluxo contínuo (enxuto) para a indústria estudada. 
Apresentando as características do processo produtivo, para a indústria-alvo do estudo, antes da mudança do sistema de manufatura com layout funcional e após ela - sistema de manufatura com layout celular (LIRA; GOMES; CAVALCANTI, 2015) -, assim como os ganhos alcançados.

Partindo dessas premissas realiza-se a fundamentação teórica, o desenvolvimento da pesquisa, a apresentação dos resultados e suas conclusões.

\section{FUNDAMENTAÇÃO TEÓRICA}

\subsection{Sistema de Manufatura Enxuta (Lean Manufacturing)}

A expressão "lean manufacturing" foi utilizada pela primeira vez pelo pesquisador do International Motor Vehicle Program (IMVP), John Krafcik, para definir o Sistema Toyota de Produção (GUINATO, 2000; WOMACK et al., 2004). Buscando definir "um sistema de produção muito mais eficiente, flexível, ágil e inovador do que a produção em massa, um sistema habilitado a enfrentar melhor um mercado em constante mudança", o pesquisador do IMVP cunhou o termo, que se tornou o termo genérico para descrever este inovador sistema de produção, o TPS (GUINATO, 2000).

A Manufatura Enxuta é uma filosofia de gerenciamento, não só da produção, mas de toda a organização, que busca oferecer aos clientes exatamente o que eles desejam: produtos de alta qualidade, baixo custo e no momento em que solicitam (SHINGO, 1996b; HERZOG; TONCHIA, 2014) realizando as atividades de forma cada vez mais eficaz, fazendo cada vez mais com cada vez menos - "menos esforço humano, menos equipamento, menos tempo e menos espaço" (WOMACK; JONES, 2004).

Princípios Fundamentais do Sistema de Manufatura Enxuta

A base do Sistema de Manufatura Enxuta é a absoluta eliminação do desperdício, que, por isso mesmo, é enxuta (OHNO, 1997). É o Principio da Subtração do Custo, como o descreve Shingo (1996b), em que o preço de venda dos produtos não é mais dado pela equação "Custo + Lucro = Preço de Venda", mas substituída por "Preço - Custo = Lucro".

$\mathrm{Na}$ primeira equação, o preço de venda é definido pelos custos para se produzir determinado item somado ao lucro pretendido. Isso implica não haver necessidade de melhorias uma vez que todo o custo gerado pela ineficiência do sistema de manufatura é agregado ao valor do produto.

A questão é que, hoje, com a acirrada concorrência dos mercados consumidores, quem dita o preço não é mais o produtor, como outrora. O TPS propõe então o principio de que o lucro é, na verdade, o preço, determinado agora pelo mercado, menos o custo.

Esta nova abordagem implica que, se uma empresa deseja manter uma determinada margem de lucro e, até mesmo, sobreviver no mercado, ela deve mover esforços implacáveis para cortar custos e, consequentemente, eliminar perdas. Ainda segundo Shingo (1996b), "O princípio da subtração do custo é o conceito mais básico do Sistema Toyota de Produção. Ele exige esforços extraordinários para a eliminação da perda".

No Sistema de Manufatura Enxuta, a eliminação dos desperdícios é alcançada de maneira sistemática. É realizada uma análise detalhada da cadeia de valor, que é a sequência de ações 
específicas para que o produto, de matéria-prima, se transforme em produto acabado, para que, determinado o fluxo de valor e identificadas às operações que não agregam valor, se possa otimizar o fluxo e eliminar os desperdícios (GUINATO, 2000).

\subsubsection{Análise do Desperdício}

Para a manufatura enxuta, desperdício é toda e qualquer atividade humana que absorve recursos, mas não agrega valor: produção de itens defeituosos ou que ninguém deseja, estoques, processamentos desnecessários, movimentação de funcionários e insumos, esperas, serviços que não atendem às necessidades do cliente, etc (WOMACK; JONES, 2004). Ohno (1997) nos convida a ter em mente que só há sentido em aumentar a eficiência de um processo quando associado a isto está uma redução de custos. Assim deve-se produzir apenas aquilo de que se necessita e com o mínimo de recursos. "A verdadeira melhoria na eficiência surge quando produzimos zero desperdício" (OHNO, 1997).

Os desperdícios identificados pelo TPS são: superprodução (LIKER; MEIER, 2007; SHINGO, 1996a); espera (LIKER; MEIER, 2007; SHINGO, 1996a; GUINATO, 2000); perda por transporte (LIKER; MEIER, 2007; SHINGO, 1996a); perda no processamento (SHINGO, 1996a); perdas no processamento(GUINATO, 2000; LIKER; MEIER, 2007); perda por estoque (LIKER; MEIER, 2007); perdas nos movimentos; perda na produção de produtos defeituosos (SHINGO, 1996a).

\subsubsection{Os Pilares do Sistema de Manufatura Enxuta}

Como anteriormente citado, para Ohno (1997), idealizador do TPS, "a base do Sistema Toyota de Produção é a absoluta eliminação do desperdício", e, segundo ele, os pilares necessários à sustentação do sistema são: Just-in-Time (OHNO, 1997; WOMACK; JONES, 2004); Autonomação ou Jidoka (OHNO, 1997; LIKER, MEIER, 2007).

A estrutura do TPS com seus dois pilares e outros componentes fundamentais do sistema é apresentada na Figura 1.

Segundo este modelo (Figura 1), apresentado por Guinato (2000), o Sistema tem o objetivo de oferecer ao cliente produtos e serviços da mais alta qualidade, com os custos mais baixos e com menor lead time possível. Paralelamente a isto mantém o ambiente de trabalho e seu quadro de trabalhadores sob uma ótica de segurança e moral dedicando-lhes especial atenção.

Cada um dos elementos mostrados na Figura 1, que formam os pilares e elementos fundamentais do TPS, é descrito nos itens abaixo. 


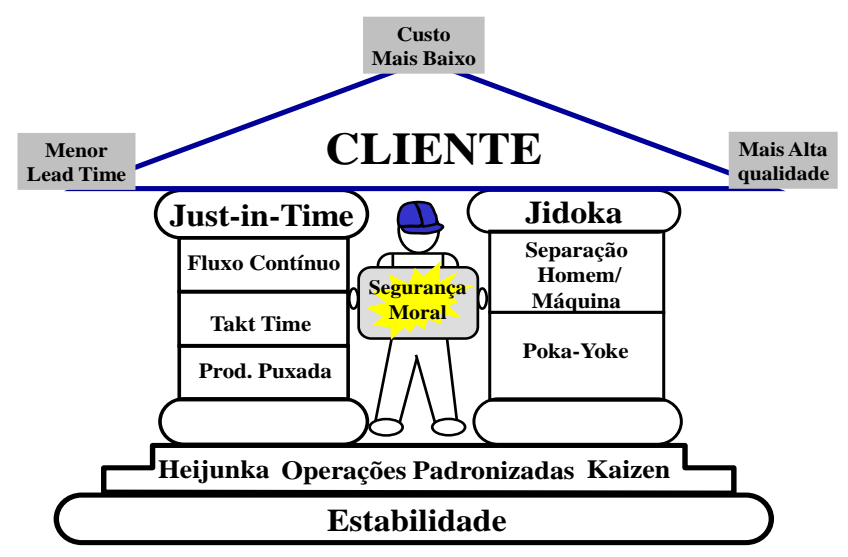

Figura 1 - A Estrutura do Sistema Toyota de Produção. Fonte: Guinato (2000).

\subsection{O Layout Industrial}

Layout, ou arranjo físico, é a disposição física dos muitos recursos de transformação envolvidos em um processo de manufatura, e de suas unidades de apoio. É a definição de onde colocar máquinas, postos de trabalho, equipamentos, pessoas e todas as instalações.

Segundo Slack; Chambers; Johnston (2002) é ainda a preocupação com o posicionamento físico de todos estes recursos, constituindo-se em umas das características mais evidentes de uma operação produtiva, por ser quem Ihe dá "forma" e aparência.

No estudo do arranjo físico busca-se a melhor maneira de dispor, em uma determinada área, todos os meios produtivos, otimizando manuseio, transporte e circulação de pessoal. Pode ser estudado no momento da implantação da empresa ou na busca por melhorias em organizações implantadas (ROCHA, 2002).

Uma série de fatores podem ser motivadores de um reestudo de layout nas empresas, todos relacionados diretamente com a situação atual da organização em relação ao mercado e clientes (internos e externos): necessidade de expansão da capacidade produtiva, custos operacionais elevados, introdução de novas linhas de produtos, necessidade de melhorias no ambiente de trabalho (por condições ergonômicas ou motivacionais, por exemplo), redução de tempos e movimentos, necessidade de flexibilidade, correções no fluxo do processo e utilização do espaço. Todos estes são fatores direta e fortemente influenciados e até atrelados ao arranjo físico (PEINADO; GRAEML, 2007).

De acordo com as necessidades e/ou objetivos da empresa e com o tipo de produto e processo, defini-se o tipo de layout a ser utilizado.

\subsubsection{Tipos Básicos de Layout}

Há vários tipos de layout industrial. A grande maioria, porém, deriva de apenas quatro tipos básicos. A maior parte dos autores que abordam o tema, entre eles: Slack; Chambers; Johnston (2002), Gaither; Frazier (2002), Peinado; Graeml (2007), Rocha (2002) e Black (1998), concordam em definir os quatro tipos básicos de layout como sendo: Layout em Linha ou por Produto, Layout Funcional ou por Processo, Layout Celular ou Células de Manufatura e Layout de Posição Fixa ou Posicional (PEINADO; GRAEML, 2007). 
Com base nos autores, acima citados, são descritas, abaixo, as características principais de cada um dos tipos de arranjo físico.

\subsection{O Sistema de Manufatura Enxuta e o Layout Industrial}

O layout industrial tem um papel fundamental dentro do Sistema de Manufatura Enxuta. Isso porque sem um layout adequado, baseado na sequência do processo (layout celular), é impossível estabelecer o fluxo contínuo e unitário que viabiliza o just-in-time, pilar da manufatura enxuta, e assim alcançar a redução dos desperdícios, seu objetivo primeiro (ANJOS, 2009; SHINGO, 1996a).

O arranjo com células de manufatura (CM) é considerado o layout moderno, que vem de encontro às exigências do mercado. Normalmente em formato de $U$, projetados para atender às necessidades dos clientes, capazes de produzir produtos rapidamente e entregando-os no prazo. São menores, com cerca de $1 / 3$ do tamanho dos layouts utilizados no passado, economizam espaço reduzindo estoques drasticamente, são compactos e flexíveis. Neles os trabalhadores são treinados para desenvolverem mais de uma atividade, têm uma melhor comunicação e moral mais elevada. Os materiais percorrem distâncias mais curtas, os custos são reduzidos e os clientes são servidos com mais eficiência. As CM possibilitam manufaturar produtos atrativos, com qualidade superior e preços competitivos (BLACK, 1998; GAITHER; FRAZIER, 2002).

A otimização do layout, a partir da adoção de células de manufatura, possibilita a eliminação, ou a máxima redução possível, dos transportes, a eliminação das esperas interprocessos e a eliminação dos inventários de produtos acabados e entre processos. Isso faz com que o lead time seja reduzido e a produção contrapedido (puxada) seja viável.

Alem disso, as CM melhoram o feedback de informações acerca da qualidade ajudando a reduzir os defeitos à zero, permite produzir no menor tamanho de lote possível dando flexibilidade ao sistema produtivo, reduz drasticamente o manuseio de materiais, reduz o tempo de setup, reduz as variações de lead time e limitações do balanceamento de linha e melhora a capabilidade e confiabilidade do processo (BLACK, 1998; SHINGO, 1996b).

A melhoria de layout é uma pré-condição fundamental para a implantação do Sistema de Manufatura Enxuta, é base para o estabelecimento de seus pilares (SHINGO, 1996a).

O caso exposto neste trabalho aborda exatamente a interação entre o sistema de manufatura enxuta e o layout fabril. A forma como se desenvolve a pesquisa e como se dá a apresentação deste caso é descrita no Capítulo 3.

\section{DESENVOLVIMENTO DA PESQUISA}

Assim, em se tratando da concretização do estudo de um caso, neste capítulo é descrito o contexto, as formas de coletas e tratamento de dados e as etapas para o desenvolvimento do caso em questão.

\subsection{Contextualização}

Fundada em 1963, a indústria de transformadores, em que é realizada esta pesquisa, atua, principalmente, no segmento chamado "distribuição". Este segmento engloba transformadores 
aéreos de 3 a 300kVA, trifásicos, principalmente, mas também monofásicos, um segmento em forte expansão, porém muito competitivo.

Pouco antes de mudar completamente seu sistema produtivo, a empresa passava por um momento turbulento de sua história enfrentando problemas de grandes atrasos e longos prazos na entrega dos produtos, níveis de controle muito abaixo do necessário, processos com elevados custos, grande quantidade de horas-extras, grandes perdas, um planejamento da produção falho com pouca previsibilidade, um alto número de funcionários compondo a mão de obra direta, um pátio fabril desorganizado, um nível elevadíssimo de inventário entre as etapas do processo e um grande número de retrabalhos.

Apesar do difícil cenário que enfrentava, a referida indústria tinha uma grande oportunidade: possuía uma boa carteira de clientes e um mercado aquecido, em forte expansão. Era preciso, então, mudar: rever o layout, rever o processo, rever a interação das áreas de apoio (PCP, engenharia de processos, manutenção etc.) com a produção, rever o quadro funcional e o fluxograma, sobretudo no chão de fábrica, enfim rever todo o sistema de manufatura e traçar novas estratégias para recuperar a produtividade, a qualidade, a confiabilidade, a competitividade e, consequentemente, os clientes e os espaços do mercado.

É neste ambiente de mudanças que está inserido o caso estudado neste trabalho.

\subsection{Metodologia}

O procedimento utilizado na pesquisa é um estudo de caso, pois esta abordagem permite aprofundar os diversos aspectos que motivaram as mudanças ocorridas na indústria citada e estudada, bem como os detalhes do processo de mudança e os resultados decorrentes do mesmo (SILVA; MENEZES, 2001).

Realizando um estudo de caso, pós-fato, é possível descrever a problemática encontrada na indústria de transformadores, o estudo realizado na busca pelas soluções para estes problemas, a implementação das soluções e a exposição dos resultados.

Os resultados, por sua vez, são obtidos a partir de uma comparação pré-fato pós-fato totalmente fundamentada em dados, coletados no chão de fábrica, por meio de apontamentos e tomadas de tempo, e levantados no sistema de produção da empresa, tornando-se, assim, possível quantificá-los.

Os dados levantados são agrupados de modo a permitir sua análise e exposição. Todos os dados são tomados para o transformador de 45kVA, escolhido como padrão.

Finalizando a fase de pesquisa, os resultados obtidos da observação individual de cada layout, funcional e celular, são tabulados para que seja realizada a comparação.

Os ganhos e perdas são, com base nestes dados, apresentados e discutidos e é possível evidenciar a validade das mudanças realizadas no processo de manufatura, provocado pelas mudanças de sistema de manufatura, arranjo físico e fluxo de operações. Estes resultados são expostos no Capítulo 4. 


\section{APRESENTAÇÃO E ANÁLISE DOS RESULTADOS: O ESTUDO DE CASO}

4.1 Apresentação dos Resultados Encontrados no Processo Fabril das PA's (parte ativa) dos Transformadores de Distribuição no Layout Funcional (Pré-Fato)

De acordo com a Figura 5, a sequência do processo de manufatura das partes-ativas, na fábrica, inicia-se pela produção das bobinas de baixa tensão (BBT). O tempo de fabricação das BBT's é de 58,8 minutos. As BBT's finalizadas são armazenadas por 0,92 dias até serem movimentadas para o processo posterior, fabricação das bobinas de alta tensão (BAT).

As BAT's são produzidas, na sequência, sobre as BBT's. Seu tempo de ciclo é de 109,9 minutos e sua permanência em inventário é de 0,94 dias até ser transportada para a prémontagem (PM). Paralelamente à fabricação das BAT's ocorre a montagem dos núcleos (MN). 0 tempo de ciclo para a MN é de 91 minutos e, como as BAT's, permanecem armazenados por 0,94 dias até que sejam movimentados à pré-montagem.

Por fim acontece, na área da pré-montagem, a montagem das bobinas nos núcleos, o fechamento do núcleo e as ligações entre as bobinas (processo de pré-montagem) formando, assim, a parte-ativa. O tempo de processamento na PM é de 143 minutos.

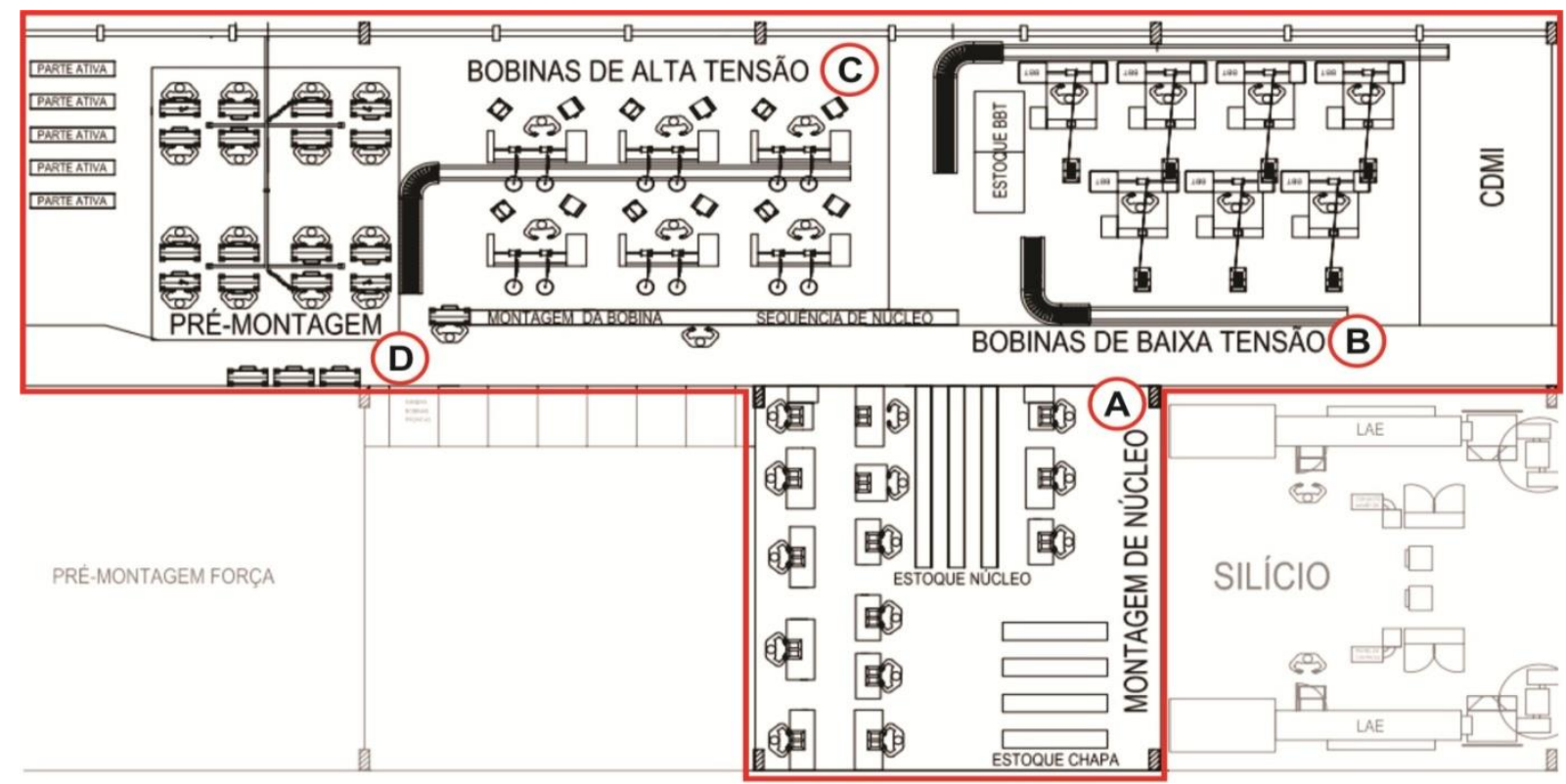

Figura 2 - Layout da área fabril das PA's dos transformadores. Fonte: Dados da empresa estudada.

O processo, como um todo, apresenta, como resultado, um lead time de 3 dias e um tempo de processamento de aproximadamente 311,7 minutos. A produção diária é de 40 unidades, com uma mão de obra direta (MOD), ou seja, envolvida no processo, de 57 pessoas (14 delas destinadas ao abastecimento de matéria prima e realização de movimentações dos subitens do processo) e uma produtividade, dada pela relação entre o número de unidades produzidas e a MOD, de 0,77 unid/func.

\subsubsection{Discussão dos Resultados Encontrados no Layout Funcional}

O processo produtivo das partes-ativas dos transformadores de distribuição trifásicos no arranjo físico funcional, praticado na empresa estudada (Figura 2), apresenta como característica 
deste arranjo físico conforme os autores citados no Capítulo 3, em primeiro lugar um nível de inventários muito elevado. Entre cada etapa do processo forma-se um inventário de subitens (BBT's, BAT's, etc.) que, na prática, toma um grande espaço e gera um alto grau de desorganização no ambiente fabril.

A formação de inventários é, ainda, uma perda não agregando valor algum ao produto e devendo ser combatido, segundo Shingo (1996b). O lead time é diretamente influenciado pelo nível de inventário mantendo, para com ele, uma relação diretamente proporcional: quanto maior o nível de inventários, mais longo o lead time (LIKER; MEIER, 2007). Os tempos em inventários encontrados na indústria estudada representam, aproximadamente, 93\% do lead time.

Uma segunda característica do processo influenciada pelo layout é o número de movimentações dos insumos e subitens. Como estes vão de processo para processo e os processos encontram-se em áreas distintas, as movimentações são em elevado número e em distâncias consideráveis.

O transporte é outra das perdas citadas pelo TPS (Sistema Toyota de Produção) e deve ser eliminado do fluxo ou reduzido ao mínimo possível (SHINGO, 1996a).

As perdas citadas acima são, apenas, as principais. Perdas por espera, superprodução, movimentos e produção de itens defeituosos ainda são encontradas gerando grandes possibilidades de melhoria.

O longo lead time e a grande quantidade de perdas do processo fez com que a empresa acumulasse, ao longo do tempo, um grande número de itens em atraso, chegando a um ápice de 2000 (dois mil) transformadores em atraso. Com uma capacidade fabril de 1000 (mil) transformadores por mês, esse valor representava um atraso de, no mínimo dois meses. Como o processo não tinha estabilidade e havia as muitas perdas citadas, esse número tenderia, na verdade, a crescer. Na prática, significava dizer, por exemplo, que, quando um cliente comprava um transformador, só o iria receber dois meses depois.

\subsection{Identificando as Mudanças Necessárias e as Possíveis Melhorias}

Para identificar o que fazer em vista da superação do difícil momento vivido pela indústria estudada, foram confrontadas duas realidades: o cenário externo (o mercado, os clientes, etc) e o ambiente interno (a produção, as áreas de apoio, etc).

Em primeiro lugar, o acirrado mercado exige produtos com preços cada vez menores que, por sua vez, implicam lucros também menores. Para permanecer competitiva a empresa precisa, então, reduzir seus custos fabris, já que o preço de venda é determinado pelo mercado. Para garantir sua margem de lucro é necessária uma redução de custos. Por outro lado, o sistema produtivo praticado pela indústria estudada é gerador de grandes perdas, como exposto no subitem 4.1. Perdas com altos níveis de inventário, com elevado número de transportes e muitas outras anteriormente citadas. As perdas agregam, aos produtos, custos desnecessários que acabam por reduzir sua margem de lucro.

Pode-se concluir que a eliminação das perdas faz-se extremamente necessária e qualquer mudança proposta deve partir deste princípio. 
Uma segunda, porém não menos importante, exigência imposta pelo mercado é um tempo de resposta menor, ou seja, prazos mais curtos.

Reduzir prazos de entrega implica reduzir o lead time. Para reduzir o lead time de fabricação dos transformadores é necessário reduzir, ou até eliminar, os inventários, responsáveis. Como o layout funcional implica a formação de inventário entre processos, é preciso buscar um layout diferente, que possibilite a redução de lead time necessária.

Outro ponto a ser observado é o fato de que o mercado consumidor não tolera produtos sem um padrão de qualidade assegurado. A desorganização encontrada no chão de fábrica da indústria é outro fator que precisa ser combatido se espera-se garantir este padrão de qualidade. Reduzir os inventários traria, também, este ganho.

A partir do exposto tem-se que: precisa haver mudanças no sistema produtivo que levem a uma redução das perdas e o layout fabril precisa migrar para um que reduza o máximo possível os níveis de inventário e melhore a qualidade e confiabilidade do processo.

Assim, a resposta para a mudança necessária é adotar um sistema de manufatura que contemple estes dois pontos principais.

O Sistema de Manufatura Enxuta propõe exatamente uma busca implacável pela eliminação do desperdício, como forma de reduzir os custos (SHINGO, 1996b). Ele propõe, ainda, a adoção de um fluxo enxuto através de células de manufatura onde se eliminam os inventários e forma-se um fluxo contínuo dos materiais dentro da célula que garanta a redução de lead time necessária e favorece a qualidade do produto (GUINATO, 2000).

A adoção do Sistema de Manufatura Enxuta surge como a solução procurada.

\subsubsection{Planejando e Executando as Mudanças}

A primeira ação para que seja implantado um Sistema de Manufatura Enxuta, segundo Black (1998), é a adoção de células de manufatura. Para que o arranjo físico funcional, então utilizado, seja convertido em células de manufatura é necessário que cada etapa necessária ao processo seja agrupada em uma mesma área (a célula) e na sequência em que são realizados.

Cada uma das áreas do layout funcional (BBT's, BAT's, etc) cederá seus recursos dividindose nas células de manufatura (PEINADO; GRAEML, 2007).

O número de recursos diretos necessário, por célula, é de oito colaboradores, uma bobinadeira de baixa tensão, duas bobinadeiras de alta tensão, duas mesas de montagem, três conjuntos de equipamentos.

Alem do balanceamento adequado, como premissa, não deve haver formação de inventário entre as etapas do processo para que o fluxo flua, assim, os inventários existentes no arranjo físico funcional, devem ser eliminados.

Outro fator importante que deve ser levado em conta é a redução das distâncias percorridas pelos materiais e a disposição de modo a permitir o fluxo contínuo, assim, o novo layout deve aproximar os recursos transformadores e dispô-los conforme as etapas do processo fabril. Esses fatores também são determinantes na geração do fluxo contínuo. 
Tomando como base a projeção da produção de uma célula, que é de 8 unid/dia, o número de 3 células representaria uma perda de produção de 40 unid/dia para 24 unid/dia. Assim, opta-se por investir em mais 6 bobinadeiras de alta tensão e formar 6 células de manufatura para se ter uma produção de 48 unidades/dia.

A partir dos dados obtidos o novo layout é projetado (Figura 3).

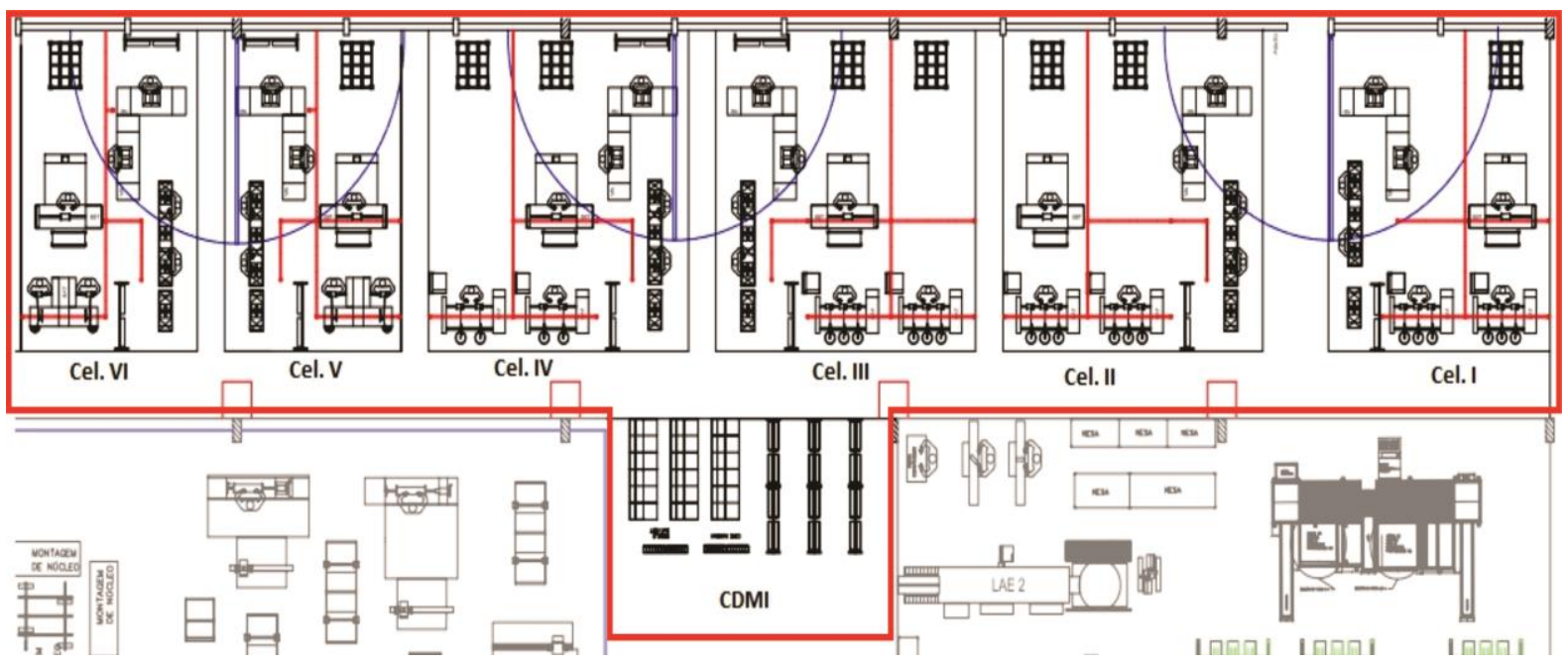

Figura 3 - Layout celular da área fabril das PA's dos transformadores. Fonte: Dados da empresa estudada.

\subsection{Os Resultados das Células}

Cada célula de manufatura tem capacidade produtiva de 8 unidades/dia, conforme o esperado, obtendo uma produção total, para as 6 células, de 48 unidades/dia.

Com as células o lead time passou a ser de 1 dia e o tempo de processamento passou a ser: 51 minutos na BBT, 108 minutos da BAT, 86 minutos na montagem de núcleo e 90 minutos na prémontagem, totalizando 249 minutos (levando em consideração o paralelismo da fabricação de BAT's e montagem de núcleos).

A mão de obra direta passa para 40 pessoas e a produtividade, em função da produtividade e MOD, é 1,2 unid/func. A área ocupada no pátio fabril passou a ser de $475 \mathrm{~m}^{2}$.

\subsection{Comparando os Resultados dos Layouts}

O layout em CM alcançou vantagem sobre o layout funcional em todos os principais aspectos produtivos: a produção diária obteve aumento de $20 \%$, passando de 40 para 48 unidades por dia, a MOD alcançou redução de aproximadamente 30\%, reduzindo 17 colaboradores do processo, a produtividade, dada em função do número de transformadores produzidos por colaborador, em média, aumentou $56 \%$, indo de 0,77 a 1,2 unid/func, o lead time, por sua vez, reduziu $67 \%$ passando de 3 a 1 dia, o tempo de processamento reduziu 20\%, diminuindo 62,7 minutos e a área fabril obteve uma redução de $24 \%$ passando de uma área de $625 \mathrm{~m}^{2}$ a uma de $475 m^{2}$.

A comparação dos resultados encontrados nos layouts funcional e celular e os ganhos obtidos são apresentados, de forma gráfica, através da Figura 4. 


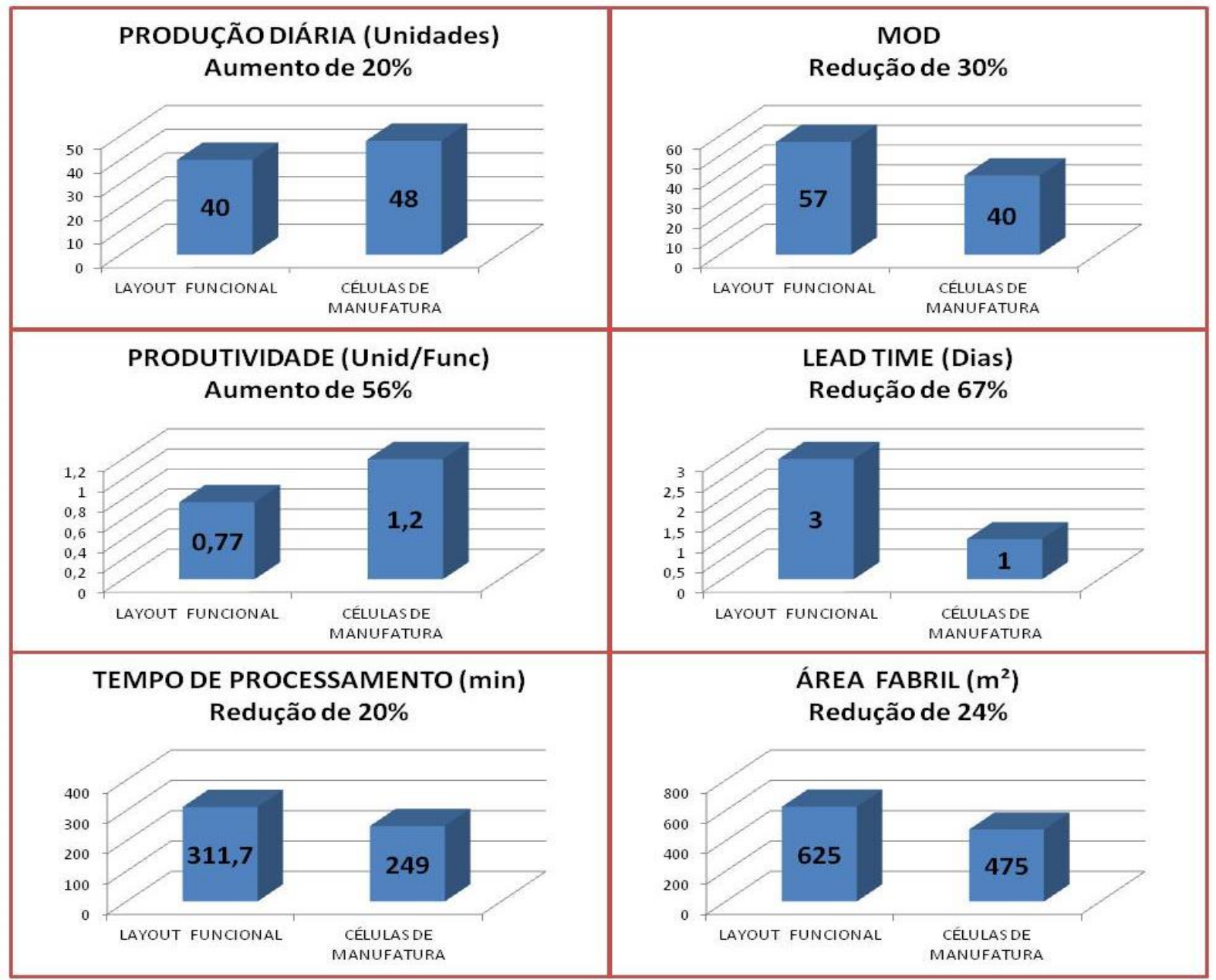

Figura 4 - Resultados da comparação entre layouts.

Fonte: Dados encontrados na empresa estudada.

Com a comparação entre os resultados encontrados em cada layout, vê-se que a mudança de processo produtivo, com a adoção do fluxo contínuo e de um layout celular, baseado nos fundamentos Sistema de Manufatura Enxuta, alcançou o resultado esperado.

Houve aumento de produtividade e redução de tempo de processamento e lead time contribuindo para a redução dos níveis de atraso. Os níveis de atraso caíram da escala de mil a dois mil transformadores para a escala de 0 a 300 transformadores.

O tempo de armazenamento constitui também fonte de desperdício. Ao reduzi-lo, reduzimos este desperdício e, consequentemente, o custo de manufatura (OHNO, 1997).

A redução da mão de obra direta também implica redução nos custos de fabricação, uma vez que é uma das partes principais da sua composição.

Ainda a redução da área fabril contribuiu para reduzir custo, uma vez que diminui as perdas com transporte, e redução de lead time, pois é um dos fatores que possibilita o fluxo contínuo (GUINATO, 2000). A redução de $3 \%$ nos níveis de retrabalho indica também aumento em qualidade.

Todos os dados encontrados atestam a redução de perdas, e consequente redução de custos, e a redução de tempo de ciclo, revelando a eficácia dos novos sistema de manufatura e arranjo físico implementados. 


\section{CONCLUSÃO}

O presente trabalho se propõe a apresentar o estudo da alteração de um layout funcional para celular motivado pelos fundamentos da manufatura enxuta através de um estudo de caso em uma indústria de transformadores, tendo como objetivo geral verificar quais os benefícios da adoção deste layout (de manufatura celular) com fluxo contínuo (enxuto) para esta indústria.

Por meio da fundamentação teórica as características destes arranjos físicos são apresentadas, bem como a influência da manufatura enxuta no layout industrial, e com o estudo de caso pôde-se obter dados e resultados que quantificaram e qualificaram a realização da alteração de arranjo físico.

Observou-se, assim, que a utilização de células de manufatura, com um fluxo enxuto, traz reais vantagens com relação ao arranjo físico funcional. Os principais benefícios encontrados foram: redução do nível de inventários e suas perdas, redução do número de transportes e suas perdas, redução do nível de atrasos de entrega, redução do número de rejeições de produtos indicando aumento de qualidade, redução do lead time em $67 \%$; e do tempo de processamento em $20 \%$, redução da mão de obra direta em $30 \%$, aumento da produção diária em $20 \%$ e da produtividade em 56\%, redução da área fabril em $24 \%$ e consequente redução de custos.

Assim, conclui-se que a utilização de um layout em células de manufatura com um fluxo enxuto trouxe benefícios e alcançou os resultados esperados nesta indústria de transformadores.

\section{REFERÊNCIAS}

1. ANEEL, A. N. D. E. E.-. Atlas de Energia Elétrica do Brasil. Brasília. 3ạ Ed. 2008.

2. ANJOS, V. D. S. C. D. Os Benefícios da Implementação da Manufatura Enxuta: Estudo de Caso em uma Empresa Automotiva. 2009. Faculdade de Ciência e Tecnologia, Salvador.

3. BLACK, J. T. O Projeto da Fábrica com Futuro. Porto Alegre: Bookman, 1998.

4. DE TREVILLE, Suzanne et al. Valuing lead time. Journal of Operations Management, v. 32, n. 6, p. 337-346, 2014.

5. DIAS, R. L. T. Conceitos de Manufatura Enxuta Aplicados a uma Indústria de Suprimentos e Dispositivos Médicos. 2006. Engenharia de Produção, Universidade Federal de Juiz de Fora, Juiz de Fora.

6. FRITZEN, Larissa de Souza Pedrosa; SAURIN, Tarcisio Abreu. Avaliação de práticas de produção enxuta em células de manufatura no setor automotivo. Produto \& Produção, v. 15, n. 4, p. 68-88, 2014.

7. GAITHER, N.; FRAZIER, G. Administração da Produção e Operações. São Paulo: Pioneira Thomson Learning, 2002.

8. GUINATO, P. Produção \& Competitividade: Aplicações e Inovações. Recife: Editora da UFPE, 2000.

9. HERZOG, Natasa Vujica; TONCHIA, Stefano. An Instrument for Measuring the Degree of Lean Implementation in Manufacturing. Strojniški vestnik-Journal of Mechanical Engineering, v. 60, n. 12, p. 797-803, 2014. 
10. LIKER, J. K.; MEIER, D. O Modelo Toyota: Manual de Aplicação. Porto Alegre: Bookman, 2007.

11. LIRA, Ana Claudia de Queiroz; GOMES, Maria de Lourdes Barreto; CAVALCANTI, Vladyr Yuri Soares de Lima. Modelo de alinhamento estratégico de produção-MAP: contribuição teórica para a área de estratégia de produção. Production, n. ahead, p. 00-00, 2015.

12. LUZZI, A. A. Uma Abordagem para Projetos de Layout Industrial em Sistemas de Produção Enxuta: Um Estudo de Caso. 2004. Escola de Engenharia, Universidade Federal do Rio Grande do Sul, Porto Alegre.

13. MME, M. D. M. E. E.-. Informativo Luz para Todos. v. Fevereiro, n³8, 2012.

14. OHNO, T. O Sistema Toyota de Produção: Além da Produção em Larga Escala. Porto Alegre: Bookman, 1997.

15. PEINADO, J.; GRAEML, A. R. Administração da Produção: Operações Industriais e de Serviços. Curitiba: UnicenP, 2007.

16. RICCl, Mayara Rohenkohl. Sistema toyota de produção: um estudo na linha de produção em uma indústria de confecção de ternos. 2014.

17. ROCHA, D. R. D. Fundamentos da Administração da Produção. Fortaleza: Gráfica LCR Ltda, 2002.

18. SHINGO, S. O Sistema Toyota de Produção. 2a ed. Porto Alegre: Bookman, 1996a.

19. Sistemas de Produção com Estoque Zero: O Sistema Shingo para Melhorias Continuas. Porto Alegre: Bookman, 1996b.

20. SILVA, E. L. D.; MENEZES, E. M. Metodologia da Pesquisa e Elaboração da Dissertação. Florianópolis: Laboratorio de Ensino a Distância da UFSC 2001.

21. SLACK, N.; CHAMBERS, S.; JOHNSTON, R. Administração da Produção. São Paulo: Atlas, 2002.

22. TUBINO, D. F. Sistemas de Produção: A Produtividade no Chão de Fábrica. Porto Alegre: Bookman, 1999.

23. WOMACK, J. P.; JONES, D. T. A Mentalidade Enxuta nas Empresas - Lean Thinking: Elimine o Desperdicio e Crie Riqueza. Rio de Janeiro: Elsevier, 2004.

24. WOMACK, J. P.; JONES, D. T.; ROSS, D. A Máquina que Mudou o Mundo. Rio de Janeiro: Editora Campus Ltda., 2004. 